\title{
Aspectos ético-legais em Imaginologia
}

\author{
Sandro Fenelon*
}

Os processos envolvendo médicos têm aumentado nas últimas décadas em todo o mundo, inclusive no Brasil. Com o desenvolvimento de novos métodos diagnósticos, como a radiologia intervencionista (diagnóstica e terapêutica), ultra-sonografia, tomografia computadorizada e ressonância magnética, o imaginologista passou a ter maior envolvimento e responsabilidade com o paciente e familiares. O diagnóstico por imagem, no Brasil, ainda não é uma das especialidades mais envolvidas em processos judiciais. Nos Estados Unidos, entretanto, a especialidade ocupa o terceiro lugar entre as mais demandadas. No nosso meio, as especialidades mais freqüentemente envolvidas em processos médicos são: ginecologia e obstetrícia, ortopedia, emergência, anestesiologia, cirurgia geral, clínica médica e pediatria.

Os motivos atribuídos ao aumento das denúncias contra os médicos são: pacientes são incapazes de distinguir as complicações de procedimentos médicos daqueles que resultam de negligência; grande expectativa em relação ao profissional médico e aos procedimentos diagnósticos e terapêuticos; enfraquecimento da relação médico-paciente nos últimos tempos; conscientização do problema pela população; surgimento de organizações em defesa do paciente; alta indenização recebida pelos pacientes, como ocorre nos Estados Unidos.

Ocasionalmente, os resultados de procedimentos e laudos médicos realizados pelos radiologistas podem provocar esclarecimentos quanto aos meios e condutas adotados (Tabela 1). A questão é que nem toda denúncia ao médico acarreta processo judicial e é realmente comprovada como "erro médico".

\section{Relatos na literatura}

Como a medicina não é uma ciência exata e até os "melhores" médicos podem errar em seus diagnósticos ou procedimentos, há inúmeros relatos de processos médicos e indenizações na literatura. Os primeiros foram feitos há mais de 50 anos.

Quaisquer métodos de imagem podem estar envolvidos, mas os mais prevalentes são a mamografia e a radiografia de tórax. As condições mais freqüentemente envolvidas em processos judiciais são fraturas, câncer de mama, pulmão e cólon, e complicações de procedimentos.

\footnotetext{
* Médico Radiologista, Diretor do portal Imaginologia Online. E-mail: fenelon@radiologista.com.br
}

Tabela 1 Condições que freqüentemente levam a processos judiciais.

Erros diagnósticos
- Erro de percepção
- Falta de conhecimento
- Julgamento equivocado
- Técnica e posicionamento inadequados
Complicações de exames
- Radiologia intervencionista
- Reações adversas ao meio de contraste
- Quedas de mesa de exame
Câncer
- Casos não diagnosticados ou atraso no diagnóstico de:
- Mama
- Pulmão
- Cólon
- Ósseo
Trauma (fraturas e luxações)
- Coluna cervical e torácica
- Osso escafóide
- Colo do fêmur
- Cabeça do rádio
- Luxação posterior do ombro
- Luxação do carpo e metatarso

Um estudo britânico (1989) avaliou 360 casos radiológicos envolvidos em negligência médica. Desses, 280 casos (78\%) eram relacionados a trauma e à não detecção de fraturas e luxações. Fraturas da coluna cervical, osso escafóide e colo do fêmur e as luxações do metatarso, carpo e posterior do ombro foram negligenciadas com maior freqüência. Nos 80 casos restantes (22\%), os erros não estavam relacionados ao trauma.

Complicações como infecção ou hemorragia após biópsia guiada por ultra-sonografia, trombose, embolismo ou hemorragia após angiografia, e aracnoidite após mielografia também estão envolvidas em processos.

Há ainda relatos de casos como queda da mesa de exame em estudos baritados (inclusive com morte em um caso), passagem intravascular (venosa) de sulfato de bário e conseqüente embolia, perfuração do cólon durante o enema opaco, e até um caso de morte por ingestão de agentes químicos acidentalmente misturados ao bário. 


\section{Responsabilidade profissional}

O médico passa a ser responsável pelo erro cometido no exercício profissional quando são evidenciados atos de imperícia, imprudência ou negligência.

Imperícia - Ocorre quando há inobservância das normas técnicas, por despreparo prático ou por insuficiência de conhecimentos. Considerar um médico imperito é discutível, tratando-se de um profissional treinado na faculdade e na residência médica por vários anos. É uma premissa que, não sendo aceita, torna-se agravante.

Imprudência - Ato ou conduta caracterizados pela precipitação, insensatez, intempestividade ou falta de cautela.

Negligência - É a forma mais freqüente e ocorre quando o médico negligencia nos cuidados médicos, ou seja, o médico deixa de praticar algum ato sabidamente necessário, provocando assim um dano ao paciente.

O médico, como qualquer cidadão, pode ainda responder penalmente quando produz um dano ao seu paciente. O Código Penal prescreve que o crime doloso é quando o agente quis o resultado ou assumiu o risco de produzi-lo. Daí surge a diferenciação entre dolo direto e dolo eventual. No dolo direto o agente quer o resultado representado como fim de sua ação. $\mathrm{O}$ dolo eventual ocorre quando o agente não quiser diretamente a realização do tipo, mas a aceita como possível ou até mesmo como provável, assumindo o risco da produção do resultado. A realização do tipo (conduta abstratamente erigida como criminosa pelo legislador penal) significa a concretização da conduta penal vedada (omitir socorro, matar alguém, não lavar a mão para evitar infecção hospitalar, etc.). O crime é culposo quando o agente deu causa ao resultado por imprudência, negligência ou imperícia.

\section{Erro diagnóstico e de percepção}

A falha no diagnóstico radiológico ("missed" radiographic diagnosis) é responsável por $70 \%$ dos processos envolvendo radiologistas nos Estados Unidos. A questão se essa falha constitui má prática tem intrigado radiologistas e chamado a atenção dos tribunais norte-americanos. A falha na detecção de anormalidades radiológicas não é necessariamente má prática nos Estados Unidos. A negligência ocorre quando o "erro" infringe os princípios básicos da interpretação radiológica e/ou é causa substancial de prejuízo à saúde do paciente. O simples fato de uma lesão ser retrospectivamente visualizada também não significa necessariamente negligência. De acordo com o Conselho Médico do Estado de Wisconsin (EUA), espera-se que um radiologista "mediano" detecte todas as lesões óbvias, mas nem todas as lesões sutis.

Alguns erros são cognitivos, isto é, resultam da má interpretação pela falta de conhecimento ou julgamento inadequado (interpretação incorreta). Existem também os erros causados pela utilização de técnica radiológica inadequada (exposição e posicionamento).

Os erros de percepção são aqueles em que as anormalidades radiológicas simplesmente não são detectadas pelo imaginologista em sua avaliação inicial. A falha na detecção geralmente é atribuída à sutileza do achado ou à sua má definição. Entretanto, o fenômeno da não visualização, de alterações "óbvias" e facilmente reconhecidas numa segunda análise, ainda não foi satisfatoriamente explicado.

Não obstante os aspectos abordados acima, um estudo publicado por Yerushalmy (1969) mostrou uma discordância de $20 \%$ entre radiologistas, analisando uma mesma radiografia em ocasiões diferentes.

\section{Laudos}

O laudo radiológico é um documento. Nele, devemos mencionar a técnica utilizada e as possíveis intercorrências ocorridas durante o procedimento. A descrição dos achados deve ser redigida de forma sucinta e completa, e quando o diagnóstico é seguro, terminar com uma impressão/conclusão. É prática desaconselhada utilizar neologismos, abreviações, preposições inadequadas e principalmente termos anatomopatológicos.

Os exames sem "laudo" somente devem ser liberados em caso de absoluta necessidade do paciente e com o intuito de promover o bem-estar deste. Infere-se que, se o médico solicitante aceita o filme sem laudo e baseia-se apenas na sua própria interpretação, é ele, então, o responsável médico-legal pelas conseqüências dessa interpretação. Um estudo realizado por Vincent e colaboradores (1988) mostrou uma taxa de 39\% de erro de diagnóstico para anormalidades clinicamente significativas, feitos por médicos não especialistas em diagnóstico por imagem. Na entrega de resultados de exames, deve-se fazer o registro para quem foi entregue o exame, seja médico, clínica ou outra pessoa.

\section{Consentimento esclarecido}

O termo de responsabilidade ou "consentimento esclarecido" é um documento em que o médico fará constar clara e ostensivamente o estado clínico, o tratamento necessário ou as possíveis complicações de um procedimento. Deve-se enfatizar ainda a necessidade da participação efetiva do paciente e familiares para o sucesso dos procedimentos médicos a serem realizados. O Conselho Federal de Medicina posiciona-se contra o chamado "consentimento esclarecido" obrigatório (Parecer $\mathrm{n}^{\mathrm{o}}$ 10/96). Esse termo por escrito, segundo o mesmo CFM, somente seria obrigatório no caso de "terapias" ainda não consagradas (Parecer 33/89).

O termo de responsabilidade por escrito poderá ser utilizado em procedimentos complexos (radiologia intervencionista), em caso de uso de meios de contraste que possam causar reações adversas e em pacientes grávidas que se submetem a exa- 
mes com radiações ionizantes. O consentimento, quando utilizado, deve ser preferencialmente obtido com certa antecedência ao procedimento e pelo médico que executará o exame. Deve ser também bem elaborado, e, se possível assinado por duas testemunhas. Esse termo de responsabilidade não exime o médico de ser processado, porém, pode ajudar em sua defesa, bem como demonstrar a responsabilidade dos envolvidos.

\section{Reações adversas ao meio de contraste}

Embora as reações adversas graves ao meio de contraste sejam raras $(0,05 \%)$, o radiologista deve estar preparado para diagnosticá-las e tratá-las, pois é nesses casos que a chance de envolvimento em um processo médico-legal aumenta.

O primeiro passo é a identificação e aplicação correta do contraste a ser utilizado. É inadmissível, por exemplo, a injeção de contraste iônico ao invés do não-iônico na mielografia. No Brasil, o médico radiologista não será responsabilizado por injeção de contraste mal aplicada por profissionais de enfermagem ou biomédicos, a não ser que ele tenha completo conhecimento de que aquele profissional não estava apto para a execução da tarefa. Os meios de contraste não-iônicos devem ser utilizados especialmente naqueles pacientes de alto risco, como os alérgicos, asmáticos, cardiopatas, com história de reações prévias ao contraste e os menores de um ano e maiores de 65 anos. No caso de extravasamento para os tecidos adjacentes ao vaso, os meios de contraste hiposmolares são mais tolerados do que os hiperosmolares.

A utilização do "consentimento esclarecido" pode ser considerada nessa situação. A pergunta que se faz é o quanto devemos informar ao paciente. Alguns autores recomendam que apenas as complicações clínicas relevantes sejam informadas. Outros acham que reações pouco freqüentes e graves (como parada cárdio-respiratória e morte) também devem ser informadas, apesar de aumentarem a ansiedade e, consequientemente, o risco de uma reação adversa.

A monitorização do paciente após a injeção do contraste deve durar no mínimo 20 minutos. O radiologista, como todo médico, deve estar preparado para socorrer os casos de reações adversas leves, moderadas ou graves. $\mathrm{O}$ curso de assistência à vida em radiologia, oferecido pelo Colégio Brasileiro de Radiologia (CBR), é uma ótima oportunidade para a reciclagem do profissional.

\section{Mamografia}

O rastreamento mamográfico é um método diagnóstico eficaz na redução na mortalidade por câncer de mama. A detecção de um processo maligno antes de sua manifestação clínica é tarefa de grande responsabilidade executada pelo radiologista. Nessa área, os problemas mais observados são a falha ou atraso no diagnóstico de câncer, não comunicação de achados relevantes e falso-positivos (biópsias cirúrgicas desnecessárias).
O primeiro passo profilático é a participação no programa de controle de qualidade em mamografia do CBR. Observações finais nos laudos, como "na presença de nódulo palpável ou outra anormalidade clínica importante, o achado negativo da mamografia não exclui a necessidade de prosseguir a investigação", também são importantes na profilaxia. É essencial uma avaliação periódica da "performance" do serviço de mamografia em diagnosticar as doenças mamárias. Alguns autores ainda recomendam que a mamografia não seja utilizada isoladamente na avaliação de nódulos mamários palpáveis e que achados das categorias 4 e 5 (BI-RADS/ACR) sejam comunicados diretamente ao médico clínico.

\section{Ultra-sonografia: quem deve realizar o procedimento?}

Em alguns países, como Estados Unidos e Inglaterra, a ultra-sonografia pode ser realizada por técnicos, tecnólogos, enfermeiros ou outros profissionais paramédicos. No Brasil, o Conselho Federal de Medicina normatizou o procedimento em 1992. A resolução CFM no $1.361 / 92$ normatiza como de exclusiva competência do médico a realização e interpretação da ultra-sonografia em seres humanos, bem como a emissão do respectivo laudo.

\section{Ultra-sonografia obstétrica e transvaginal}

O número de exames ultra-sonográficos obstétricos tem crescido significativamente nos últimos anos, chegando a ser realizado rotineiramente em todas as gestantes em alguns países. Não obstante, mais de $80 \%$ dos processos médicos envolvendo a ultra-sonografia provêm de casos obstétricos. Radiologistas e ultra-sonografistas que realizam ultra-sonografia obstétrica nível 1 devem ser igualmente competentes na realização da ultra-sonografia nível 2. Esses profissionais não podem apoiar-se na premissa de que realizam apenas exames "básicos", já que também devem estar aptos a identificar anormalidades anatômicas sutis. Além disso, não está implícito que os equipamentos utilizados no nível 1 sejam de menor qualidade que do nível 2.

Algumas recomendações podem ser seguidas, objetivando uma proteção contra possíveis queixas. Quando uma anormalidade é suspeitada, obtenha uma segunda opinião e/ou realize exames seriados. A documentação do exame também é fundamental. Imagens representativas de estruturas fetais normais ou anormais, posição fetal, placenta e volume do líquido amniótico devem ser bem documentadas, por meio de vídeo ou fotos. Descreva com detalhe, em seu relatório, as estruturas anatômicas normais visualizadas e não deixe de citar aquelas que não foram adequadamente identificadas.

A ultra-sonografia transvaginal, exame que geralmente causa constrangimento à paciente, deve ser sempre realizada na presença de um atendente ou acompanhante. Antes de iniciar o exame, é indispensável explicar à paciente como é realizado o exame. 


\section{Comunicação de achados imaginológicos significativos ou urgentes}

Tradicionalmente, o imaginologista acredita que o seu papel de comunicar os resultados de exames não vai além do relatório escrito e da sua assinatura. Como forma de cortesia e boa prática médica, deve-se utilizar da comunicação verbal direta com o médico que solicitou o exame, seja através do telefone ou da comunicação pessoal. Essa conduta é ainda imprescindível quando os achados são significativos ou requerem conduta médica urgente.

\section{Internet}

A Internet é hoje uma das principais ferramentas utilizadas pelos imaginologistas, seja para a troca de informações ou no aperfeiçoamento do conhecimento. Essa nova tecnologia também possui um enorme potencial de aplicação na prestação de serviços médicos e principalmente em Imaginologia. No caso da telerradiologia (transmissão de imagens de exames via rede), é necessário preservar o sigilo médico das imagens transmitidas, através de sistemas tecnológicos de segurança avançados. O consentimento prévio do paciente também é aconselhado, já que a elaboração do laudo será realizada por um outro profissional e em outra localidade.

Enfim, desde que sejam respeitados o segredo médico, o consentimento do paciente e observadas as implicações médicolegais, quaisquer aplicações na área da Radiologia seriam possíveis através da Internet.

\section{Precauções}

A intenção do artigo não é causar ansiedade na comunidade radiológica, mas alertar os profissionais do diagnóstico por imagem da necessidade de cooperação mútua e educação continuada. Melhor do que se defender de um processo, é preveni-lo. É o chamado gerenciamento de riscos ou "risk management", que visa diminuir a chance de envolvimento em um processo médicolegal, além de aumentar as chances de defesa do profissional ou instituição e melhorar o cuidado médico com o paciente. $\mathrm{O}$ objetivo é evitar transtornos psicológicos, dúvidas em relação à própria qualidade profissional, despesas com processos e advogados, aborrecimento, perda de tempo, etc. Por outro lado, caso haja o envolvimento em um processo judicial, devemos enfrentá-lo juntamente com a orientação dos conselhos regionais de medicina e das sociedades de radiologia.

Algumas recomendações gerais que se seguem poderão ajudar os profissionais da imagem a alcançar os objetivos do "risk management":

Mantenha uma boa relação médico-paciente. No caso do imaginologista, a informação prévia e clara ao paciente (artigos 46 e 56 do Código de Ética Médica) sobre os objetivos, características e riscos do procedimento médico a ser realizado é a ferramenta mais importante e eficaz. Sempre trate-o com respeito e evite comunicar-se utilizando termos técnicos.

Documente os procedimentos realizados em prontuário médico. A comunicação verbal ao médico clínico e as condutas diante de reações adversas ao meio de contraste também devem ser assinaladas.

Reúna o maior número de informações possíveis sobre o paciente, antes da elaboração do laudo. É muito importante a discussão do caso com o clínico.

Utilize técnica radiológica adequada (posicionamento e exposição). Ajude os técnicos e tecnólogos a atingirem um ótimo padrão de qualidade.

Atualize-se e participe dos programas de educação médica continuada.

Agradecimento especial ao advogado Reinaldo André Montenegro (Assessor jurídico da Associação Médica de Minas Gerais e da Jurismed Ltda).

\section{Leitura recomendada}

1. Berlin L. Does the "missed" radiographic diagnosis constitute malpractice? Radiology 1977;123:523-7.

2. Craig JOMC. The Knox lecture: radiology and the law. Clin Radiol 1989;40:343-6.

3. Hopper KD, Tyler HN Jr. Informed consent for intravascular administration of contrast material: how much is enough? Radiology 1989;171:50914

4. Filly RA. Level 1, level 2, level 3 obstetric sonography: I'll see your level and raise you one. Radiology 1989;172:312.

5. Potchen EJ, Bisesi MA, Sierra AE, Potchen JE. Mammography and malpractice. AJR 1991;156:478-80.

6. Renfrew DL, Franken EA Jr, Berbaum KS, Weigelt FH, Abu-Yousef MM. Error in radiology: classification and lessons in 182 cases presented at a problem case conference. Radiology 1992;183:145-50. 